\title{
FAKTOR-FAKTOR YANG MEMPENGARUHI KEPUTUSAN PEMBELIAN PROLL TAPE PADA UD. PRIMADONA JEMBER
}

\author{
Shanti Maulina Ningrum, Ratih Puspitorini Y.A dan Wenny Dhamayanthi * \\ *Jurusan Manajemen Agribisnis, Politeknik Negeri Jember
}

\begin{abstract}
This research title is Factors - Factors Affecting Purchase Decision Proll Tape in UD. Primadona Jember .The purpose of this research is to analyze and test the effect of independent variables simultaneously, partially and the variables that affect the dominant on purchasing decisions proll tape. This study took a sample of 40 respondents. Data were analyzed using statistical software SPSS version 16 with multiple linear regression model. Before analyzing the multiple linear regression to tested the validity and reliability. The results of the research conducted showed that regression testing $\mathrm{F}$ test showed that all independent variables have a significant effect on purchasing decisions. Regression testing test showed that the independent variables that affect the purchasing decisions of the variable packaging. While independent variables were not significant effect of variable price and taste. Dominant variable in affecting purchasing decisions in UD. Primadona is variable packaging.
\end{abstract}

Keywords: price, taste, and packing

\begin{abstract}
ABSTRAK
Penelitian ini berjudul Faktor - Faktor yang Mempengaruhi Keputusan Pembelian Proll Tape Pada UD. Primadona Jember. Tujuan peneliitian ini yaitu untuk menganalisis dan menguji ada tidaknya pengaruh variabel-variabel bebas secara serempak, secara parsial dan variabel yang berpengaruh dominan terhadap keputusan pembelian proll tape. Penelitian ini mengambil sampel sebanyak 40 responden. Data yang diperoleh dianalisis menggunakan bantuan software SPSS versi 16 dengan model regresi linear berganda. Sebelum menganalisis regresi linear berganda dilakukan uji validitasdan reliabilitas. Hasil dari penelitian yang dilakukan menunjukkan bahwa pengujian regresi uji $\mathrm{F}$ menunjukkan bahwa seluruh variabel bebas berpengaruh signifikan terhadap keputusan pembelian. Pengujian regresi uji t menunjukkan bahwa variabel bebas yang berpengaruh terhadap keputusan pembelian yaitu variabel kemasan, sedangkan variabel bebas yang berpengaruh tidak signifikan yaitu variabel harga dan rasa. Variabel yang dominan dalam mempengaruhi keputusan pembelian pada UD. Primadona yaitu variabel kemasan.
\end{abstract}

Kata Kunci : Harga, Rasa, Kemasan terhadap keputusan pembelian. 


\section{PENDAHULUAN}

\section{Latar Belakang}

Perilaku konsumen di zaman sekarang cenderung berubah-ubah. Tentunya hal ini juga tidak lepas dari kemajuan ekonomi di negaranegara Asia, yang memberi dampak pada peningkatan pendapatan individual, sehingga konsumen di zaman sekarang lebih berorientasi pada nilai suatu produk dari pada harganya.

UD PRIMADONA merupakan perusahaan home industri yang terletak di Jl. Trunojoyo No. 137 Jember. UD Primadona bergerak di bidang jasa penjualan produk oleh-oleh khas Jember, beberapa produk yang di jual di UD Primadona yaitu, brownis, suwar-suwir, kripik tempe, proll tape dll.

Produk proll tape adalah produk yang sudah dikenal oleh masyarakat Jember bahkan luar Jember karena proll tape adalah kue khas Jember. Proll tape adalah kue yang terbuat dari bahan dasar tape, proll tape ini terdapat beberapan macam varian yaitu original, kismis, keju serta misis.

Sifat karakteristik produk merupakan sifat fisik yang melekat pada suatu produk. Karakteristik produk prol tape ini merupakan hal yang sangat mempengaruhi konsumen suka tidaknya terhadap produk olahan tape. Karakteristik produk proll tape diantaranya sebagai berikut: Rasa, harga, kemasan.

Keputusan pembelian merupakan bagian dari serangkaian proses pembelian yang sudah mengalami berbagai tahapan mulai dari mengenali masalah, pencarian informasi, evaluasi alternatife, keputusan pembelian dan perilaku pasca pembelian (Armstrong dan Kotler, 2008).

\section{Rumusan Masalah}

Berdasarkan uraian latar belakang, maka dapat dirumuskan masalah sebagai berikut :

1. Apakah variabel Harga, Rasa dan Kemasan berpengaruh secara serempak terhadap keputusan pembelian konsumen proll tape ?

2. Apakah variabel Harga, Rasa dan Kemasan berpengaruh secara parsial terhadap keputusan pembelian konsumenproll tape?

3. Variabel manakah yang mempunyai pengaruh paling dominan terhadap keputusan pembelian konsumen proll tape?

\section{Tujuan Penelitian}

Berdasarkan latar belakang dan rumusan masalah yang telah dikemukakan adapun tujuan dari penelitian ini :

1. Untuk mengetahui pengaruh Harga, Rasa dan Kemasan secara serempak terhadap keputusan pembelian konsumen proll tape.
2. Untuk mengetahui pengaruh Harga, Rasa dan Kemasan secara parsial terhadap keputusan pembelian konsumen proll tape.

3. Untuk mengetahui variabel yang mempunyai pengaruh paling dominan terhadap keputusan pembelian konsumen proll tape.

\section{Manfaat Penelitian}

Penelitian ini diharapkan dapat memberikan informasi mengenai Faktor-Faktor yang Mempengaruhi Keputusan Pembelian Prol Tape pada UD. Primadona Jember.

1. Bagi Penulis

Manfaat bagi penulis yaitu sebagai tambahan pengetahuan tentang perilaku konsumen dalam melakukan Keputusan Pembelian proll tape.

2. Bagi Perusahaan

Hasil penelitian ini diharapkan bisa menjadi bahan masukan sebagai pertimbangan dalam pengambilan keputusan yang terkait dengan strategi pemasaran perusahaan.

3. Bagi Pihak - pihak lain

Penelitian ini diharapkan dapat menjadi bahan referensi untuk penelitian selanjutnya mengenai Faktor-Faktor yang Mempengaruhi Keputusan Pembelian.

\section{METODE PENELITIAN \\ Rancangan Penelitian}

Metode dalam penelitian ini adalah penelitian survei, yaitu penelitian yang mengambil sampel dari satu populasi dan menggunakan kuisioner sebagai alat pengumpulan data pokok.

\section{Populasi Penelitian dan Teknik Pengambilan Sampel Populasi \\ Populasi adalah wilayah generalisasi} yamg terdiri atas objek atau subjek yang mempunyai kualitas dan karakteristik tertentu yang dterapkan oleh peneliti untuk dipelajari dan kemudian ditarik kesimpulannya (Sugiyono, 2009). Populasi pada penelitian ini adalah konsumen produk Prol Tape yang datang ke UD Primadona yang terlentak di Jl. Trunojoyo No. 137 Jember.

\section{Teknik Pengambilan Sampel}

Teknik pengambilan sample yang digunakan dalam penelitian ini adalah Probability sampling. Pada penelitian ini peneliti mengunakan Proportionate Stratified Random Sampling sebagai teknik pengambilan sample, yaitu populasi mempunyai anggota/unsur yang tidak homogen dan berstrata porposional (Sugiyono, 2011) 
Menurut Roscoe dalam Sugiyono (2011), bila dalam penelitian akan melakukan analisis dengan multivariate (korelasi atau regresi berganda misalnya), maka jumlah anggota sampel minimal 10 kali dari jumlah variable yang diteliti. Misalnya variable penelitiannya ada 5 (independen+dependent), maka jumlah anggota sampel $=10 \times 5=50$.

Berdasarkan hal itu, maka dalam penelitian ini, responden yang diambil berjumlah 40 responden secara proposional atau seimabang. Jumlah 40 itu didapat dari jumlah variabel (harga, rasa, kemasan dan keputusa pembelian) x 10 .

\section{Variabel Penelitian \\ Klasifikasi Variabel}

Berdasarkan pokok permasalahan yang diajukan maka variabel-variabel yang dianalisis dapat dikelompokkan menjadi :

a. Variabel Bebas (X)

Variabel bebas dalam penelitian ini adalah karakteristik produk dari prol tape yaitu:

$\begin{array}{ll}\mathrm{X}_{1} & \text { : Harga } \\ \mathrm{X}_{2} & \text { : Rasa } \\ \mathrm{X}_{3} & \text { : Kemasan }\end{array}$

b. Variabel terikat (Y)

Variabel terikat dalam penelitian ini adalah Keputusan Pembelian produk prol tape

\section{Definisi Operasional Variabel}

Berdasarkan pokok permasalahan yang diajukan, maka variable-variabel yang dianalisis dapat dikelompokan sebagai berikut :

1. Sifat Karakteristik produk adalah ciri - ciri yang melekat dari produk :

a. Harga $\left(\mathrm{X}_{1}\right)$ merupakan jumlah yang ditagihkan atas suatu produk atau jasa. Indikator yang digunakan untuk menjelaskan variabel Harga yaitu:

1) Ketetapan harga yang sesuai dengan keinginan konsumen.

2) Kesesuaian kualitas dengan Harga.

b. Rasa $\left(\mathrm{X}_{2}\right)$ merupakan rangsangan yang diterima oleh otak karena rangsangan elektriks yang diteruskan ke indra perasa, setelah mengkonsumsi prol tape maka konsumen akan merasakan rasa gurih dan manis dari produk prol tape itu sendiri. Indikator yang digunakan untuk menjelaskan variabel Rasa yaitu:

1) Rasa enak dan gurih setelah mengkonsumsi produk prol tape

2) Kekuatan dari segi rasa tape yang terdapat dalam produk prol tape

c. Kemasan $\left(\mathrm{X}_{3}\right)$ merupakan respon konsumen terhadap desain kemasan dari produk prol tape yang menarik dari segi warna, grafik, artistik bentuk kemasan produk prol tape dan penyampaian informasi, agar mudah diingat. Indikator yang digunakan untuk menjelaskan variabel kemasan:

1) Estetika (warna, grafik, artistic, dan bentuk) Kemasan yang menarik.

2) Penyampaian informasi yang menerangkan tentang produk prol tape.

2. Keputusan Pembelian

Keputusan pembelian merupakan tindakan yang dilakukan konsumen untuk membeli produk prol tape. Indikator yang digunakan untuk menjelaskan variabel Keputusan Pembelian :

1) Memprioritaskan pembelian prol tape.

2) Membeli karena adanya kebutuhan dan keinginan konsumen

\section{Instrumen Penelitian}

Data penelitian yang digunakan dalam penelitian ini yaitu data primer dan sekunder.

Penelitian yang digunakan ini merupakan analisis kuantitatif dalam bentuk checklist dengan memberi tanda $(\sqrt{ })$ sebagai bentuk instrument penelitian, maka jawaban-jawaban dari pilihan tersebut diberikan skor sebagai berikut:
a. Sangat Setuju : Skor 4
b. Setuju : Skor 3
c. Tidak Setuju : Skor 2
d. Sangat Tidak Setuju : Skor 1

\section{Lokasi dan Waktu Penelitian}

Penelitian dilaksanakan di UD Primadona yang terlentak di Jl. Trunojoyo No. 137 Jember.

\section{Prosedur Pengumpulan Data}

Metode pengumpulan data yang digunakan adalah (Sugiono 2009):
a. Observasi
b. Metode Kuesioner
c. Studi pustaka

\section{Teknik Analisis Uji Validitas}

Validitas adalah suatu ukuran yang menunjukan tingkat-tingkat kevalidan atau kesahihan sesuatu instrumen.Suatu instrumen yang valid atau sahih mempunyai validitas tinggi. Sebaliknya, instrumen yang kurang valid berarti memiliki validitas rendah.

Untuk menguji validitas dari pertanyaan, dengan taraf signifikansi $(\alpha)=5 \%$ digunakan rumus koefisien korelasi product moment (Arikunto, 2006).

$r_{x y}=\frac{\mathrm{N} \sum X Y-\left(\sum X\right)\left(\sum Y\right)}{\left.\sqrt{\{N} \sum X^{2}-\left(\sum X^{2}\right)\right\}\left\{N \sum Y^{2}-\left(\sum Y^{2}\right)\right\}}$

Keterangan :
$\mathrm{r}$
$=$ Koefisien korelasi
$\mathrm{x} \quad=$ Variabel independen 


$$
\begin{array}{ll}
\mathrm{y} & =\text { Variabel dependen } \\
\mathrm{n} & =\text { Jumlah sampel }
\end{array}
$$

\section{Uji Reliabilitas}

Suatu kuisioner dikatakan reliable atau handal jika jawaban seseorang terhadap pertanyaan adalah konsisten atau stabil dari waktu ke waktu (Sugiyono,2009).

Nunnally dalam Ghozali (2005), mengemukakan bahwa pengukuran reliabilitas dapat dilakukan dengan menggunakan One Shot atau pengukuran sekali saja, SPSS memberikan fasilitas untuk mengukur reliabilitas dengan uji statistik Cronbach Alpha (@). Suatu konstruk atau variabel dikatakan reliabel jika memberikan nilai Cronbach Alpha > 0.60.

\section{Metode Analisis Data}

\section{Analisis Regresi Linear berganda}

Data yang telah dikumpulkan, dianalisis dengan regresi berganda. Analisis regresi berganda adalah alat untuk mengetahui ada tidaknya pengaruh signifikan dua atau lebih variabel bebas $\left(\mathrm{X}_{1}, \mathrm{X}_{2}, \mathrm{X}_{3}, \ldots \ldots \ldots \mathrm{X}_{\mathrm{n})}\right.$ terhadap variabel terikat $(\mathrm{Y})$ (Sunyoto, 2012). Rumus pengujian regresi linier berganda:

$$
\begin{aligned}
& b_{2} x_{2}+b_{3} x_{3}+e \\
& \text { Keterangan : } \\
& \mathrm{Y} \quad=\text { Keputusan Pembelian Konsumen } \\
& \mathrm{a} \quad=\text { Konstanta } \\
& \mathrm{b} \quad=\text { Koefisien dari variabel bebas }(\mathrm{X}) \\
& \mathrm{X}_{1}=\text { Harga } \\
& \mathrm{X}_{2} \quad=\text { Rasa } \\
& \mathrm{X}_{3}=\text { Kemasan } \\
& e \quad=\text { Kesalahan Pengganggu }
\end{aligned}
$$

\section{Analisis Koefisien Determinasi}

Koefisien determinasi $\left(\mathrm{R}^{2}\right)$ pada intinya mengukur seberapa jauh kemampuan model dalam menerangkan variasi variabel dependen. Nilai koefesien determinasi adalah antara nol dan satu (Imam Ghozali, 2005).

$$
\begin{aligned}
& \text { Adjusted__ } R^{2}=\frac{(n-1)}{(n-k)} \\
& \text { Keterangan : } \\
& \mathrm{R}^{2}=\text { Koefisien Penentuan Berganda } \\
& \mathrm{n}=\text { Banyaknya Responden } \\
& \mathrm{k}=\text { Banyaknya Variabel Bebas }
\end{aligned}
$$

\section{Uji F}

Uji F digunakan untuk menguji tingkat signifikan pengaruh keseluruhan variabel-variabel bebas (X) terhadap variabel terikat (Y) secara bersama-sama (Sugiyono, 2011).
Kriteria pengujian hipotesisnya, apabila taraf signifikan $F_{\text {hitung }} \leq 0,05$, maka variabel independen secara serempak mempengaruhi variabel dependen secara signifikan. Apabila taraf signifikan $F_{\text {hitung }} \geq 0,05$, maka variabel independen secara serempak tidak mempengaruhi variabel dependen secara signifikan.

\section{Uji t}

Uji $t$ digunakan untuk mengetahui signifikan atau tidaknya pengaruh antara variabel bebas (X) terhadap variabel terikat (Y). Pengujian dilakukan dengan bantuan aplikasi SPSS 16. Apabila taraf signifikan $t_{\text {hitung }} \leq 0,05$, maka variabel independen secara parsial mempengaruhi variabel dependen secara signifikan.Apabila taraf signifikan $t_{\text {hitung }} \geq 0,05$, maka variabel independen secara parsial tidak mempengaruhi variabel dependen secara signifikan.

\section{HASIL DAN PEMBAHASAN \\ Hasil Uji Validitas dan Uji Reliabilitas \\ Hasil Uji Validitas}

Berdasarkan analisis dapat diketahui bahwa nilai taraf signifikan r-hitung untuk variabel Harga, Rasa, Kemasan dan Keputusan pembelian memiliki nilai signifikan $<(0,05)$, sehingga pertanyaan-pertanyaan yang diberikan dan dijawab oleh responden dinyatakan valid.

\section{Hasil Uji Reliabilitas}

Berikut ini hasil pengujian reliabilitas instrumen penelitian :

Tabel 1 Uji Reliabilitas :

\section{Reliability Statistics}

\begin{tabular}{|l|l|}
\hline $\begin{array}{l}\text { Cronbach's } \\
\text { Alpha }\end{array}$ & N of Items \\
\hline .775 & 8 \\
\hline
\end{tabular}

Sumber : Data Uji Reliabilitas

Berdasar tabel 1 tersebut diatas dapat diketahui bahwa koefisien cronbach alpha sebesar 0,775 dan melebihi 0,60 sehingga instrumen penelitian tersebut dapat dikatakan reliabel. 
Coefficients $^{\mathrm{a}}$

\begin{tabular}{|c|c|c|c|c|c|}
\hline \multirow[b]{2}{*}{ Model } & \multicolumn{2}{|c|}{$\begin{array}{l}\text { Unstandardized } \\
\text { Coefficients }\end{array}$} & \multirow{2}{*}{$\begin{array}{l}\text { Standardized } \\
\text { Coefficients }\end{array}$} & \multirow[b]{2}{*}{$\mathrm{t}$} & \multirow[b]{2}{*}{ Sig. } \\
\hline & B & $\begin{array}{l}\text { Std. } \\
\text { Error }\end{array}$ & & & \\
\hline $\begin{array}{ll}1 & \text { (Constant } \\
& \text { ) }\end{array}$ & $\begin{array}{l}2.33 \\
2\end{array}$ & 1.043 & & $\begin{array}{l}2.2 \\
37\end{array}$ & .032 \\
\hline $\begin{array}{l}\text { TOTAL } \\
\mathrm{X} 1\end{array}$ & .222 & .185 & .240 & $\begin{array}{l}1.2 \\
00\end{array}$ & .238 \\
\hline $\begin{array}{l}\text { TOTAL_ } \\
\text { X2 }\end{array}$ & .053 & .189 & .053 & $\begin{array}{l}.27 \\
7\end{array}$ & .783 \\
\hline $\begin{array}{l}\text { TOTAL_ } \\
\text { X3 }\end{array}$ & .399 & .170 & .378 & $\begin{array}{l}2.3 \\
44\end{array}$ & .025. \\
\hline
\end{tabular}

a. Dependent Variable: TOTAL_Y

\section{Hasil Analisis \\ Analisis Regresi Linier Berganda}

Berdasarkan perhitungan maka persamaan regresi linier berganda dapat dilihat pada tabel 2. Tabel 2 Hasil Analisis Regresi linear Berganda : Sumber : Data Hasil Uji Regresi LiniearBerdasarkan hasil perhitungan menggunakan SPSS 16 didapat persamaan regresi sebagai berikut $: Y=2.332+\mathbf{0 , 2 2 2 X} \mathbf{X}_{1}+\mathbf{0 , 0 5 3 X}_{2}+$ $\mathbf{0}, \mathbf{3 9 9}_{3}+\mathrm{e}$

Dari persamaan regresi diatas dapat dijelaskan bahwa :

1. Nilai Konstanta sebesar 2,332

Nilai konstanta bernilai positif menunjukkan apabila tidak ada faktor - faktor harga $\left(\mathrm{X}_{1}\right)$, rasa $\left(\mathrm{X}_{2}\right)$, kemasan $\left(\mathrm{X}_{3}\right)$, maka keputusan pembelian (Y) sebesar 2,332.

2. Nilai Koefisien Harga $\left(X_{1}\right)$ sebesar 0,222

Nilai Koefisien Harga $\left(\mathrm{X}_{1}\right)$ bernilai positif sebesar 0,222 hal ini menunjukkan bahwa setiap terjadi peningkatan harga maka akan meningkatkan keputusan pembelian sebesar 0,222

3. Nilai Koefisien Rasa $\left(\mathbf{X}_{2}\right)$ sebesar 0,053

Nilai Koefisien Rasa $\left(\mathrm{X}_{2}\right)$ bernilai positif sebesar 0,053 artinya jika Rasa meningkat, dalam arti bahwa rasa Proll Tape mengalami perubahan rasa dan inovasi rasa sesuai dengan selera konsumen, maka Keputusan Pembelian produk Proll Tape akan meningkat sebesar 0,053 satuan

4. Nilai Konstanta Kemasan ( $\left.X_{3}\right)$ sebesar 0,399 Nilai Koefisien Kemasan $\left(\mathrm{X}_{3}\right)$ bernilai positif sebesar 0,399 hal ini menunjukkan bahwa setiap terjadi peningkatan kemasan maka akan meningkatkan keputusan pembelian sebesar 0,399

Analisis Koefisien Determinasi (adjusted $R^{2}$ )
Koefisien Determinasi $\left(R^{2}\right)$ dipergunakan untuk mengetahui kontribusi koefisien variabel bebas yaitu Harga $\left(\mathrm{X}_{1}\right)$, Rasa $\left(\mathrm{X}_{2}\right)$, Kemasan $\left(\mathrm{X}_{3}\right)$, dengan variabel keputusan pembelian (Y).

Tabel 3 Koefisien Determinasi (Adjusted $R$ Square) antara Variabel Bebas (X) dan Variabel Terikat (Y) :

Model Summary

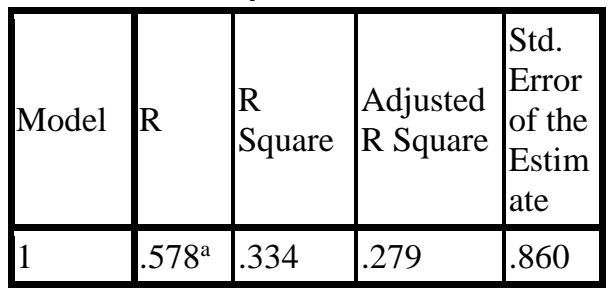

a. Predictors: (Constant), TOTAL_X3,

TOTAL_X2, TOTAL_X1

Sumber : Data Hasil Uji Regresi Linear Berganda

Intrepretasi dari hasil analisis tersebut adalah diperoleh nilai koefisien determinasi adjusted $R^{2}$ sebesar 0,279 atau $27,9 \%$. Hal ini berati bahwa perubahan variabel terikat keputusan pembelian (Y) disebabkan oleh faktor perubahan variabel bebas yaitu Harga $\left(\mathrm{X}_{1}\right), \operatorname{Rasa}\left(\mathrm{X}_{2}\right)$, Kemasan $\left(X_{3}\right)$, hanya sebesar $27,9 \%$. Sedangkan sisanya sebesar $72,1 \%$ dipengaruhi oleh faktor lain diluar variabel dalam penelitian ini.

Sedangkan untuk nilai $\mathrm{R}$ yaitu sebesar $0,578^{\mathrm{a}}$ artinya korelasi atau hubungan antara variabel harga $\left(\mathrm{X}_{1}\right)$, rasa $\left(\mathrm{X}_{2}\right)$, kemasan $\left(\mathrm{X}_{3}\right)$,terhadap keputusan pembelian sebesar 0,578. Sehingga dapat disimpulkan bahwa korelasi antara variabel bebas $(\mathrm{X})$ terhadap variabel terikat $\mathrm{Y}$ termasuk dalam kategori sedang karena berada pada rentang angka antara 0,40-0,599.

Tabel 4 Pedoman Untuk Memberikan Interprestasi Terhadap Koefisien Korelasi :

\begin{tabular}{ll}
\hline $\begin{array}{l}\text { Interval } \\
\text { Koefisien }\end{array}$ & $\begin{array}{l}\text { Tingkat } \\
\text { Hubungan }\end{array}$ \\
\hline $0,00-0,199$ & Sangat rendah \\
$0,20-0,399$ & Rendah \\
$\mathbf{0 , 4 0}-\mathbf{0 , 5 9 9}$ & Sedang \\
$0,60-0,799$ & Kuat \\
$0,80-1,000$ & Sangat Kuat \\
\hline
\end{tabular}

Sumber: Sugiyono (2009)

\section{Pengujian Uji F}

Hasil perhitungan Uji F dapat dilihat pada tabel 6 dibawah ini :

Tabel 5 Hasil Uji F : ANOVA $^{b}$

\begin{tabular}{|l|l|l|l|l|l|}
\hline Model & $\begin{array}{l}\text { Sum of } \\
\text { Squares }\end{array}$ & Df & $\begin{array}{l}\text { Mean } \\
\text { Square }\end{array}$ & F & Sig. \\
\hline
\end{tabular}




\begin{tabular}{|ll|l|l|l|l|l|}
\hline 1 & Regression & 13.372 & 3 & 4.457 & 6.026 & $.002^{\mathrm{a}}$ \\
& Residual & 26.628 & 36 & .740 & & \\
Total & 40.000 & 39 & & & \\
\hline
\end{tabular}

a. Predictors: (Constant), TOTAL_X3,

TOTAL_X2, TOTAL_X1

b. Dependent Variable: TOTAL_Y

Sumber: data di olah 2015

Perhitungan $\mathrm{F}_{\text {hitung }}$ dan $\mathrm{F}_{\text {tabel }}(\mathrm{n}=40, \alpha=0,05)$

$\mathrm{F}_{\text {hitung }}=6,026>\mathrm{F}_{\text {tabel }}=2,86$

Berdasarkan tabel diatas dapat di ketahui bahwa nilai $F_{\text {hitung }}$ sebesar 6,026dengan tingkat signifikan 0.002. Nilai $F_{\text {hitung sebesar 6,026> }}$ dengan nilai $\mathrm{F}_{\text {tabel }}$ sebesar 2.86 dan nilai signifikan nilai $F_{\text {hitung }}$ sebesar $0.002<$ dari taraf signifikan 0.05 maka variabel harga $\left(\mathrm{X}_{1}\right)$, rasa $\left(\mathrm{X}_{2}\right)$, kemasan $\left(\mathrm{X}_{3}\right)$, secara bersama - sama berpengaruh terhadap variabel terikat yaitu keputusan pembelian.

\section{Pengujian Uji t}

Berdasarkan hasil analisis regresi linear berganda pada tabel 3 dapat dijelaskan bahwa:

1. Variabel harga $\left(\mathrm{X}_{1}\right)$ mempunyai nilai signifikan 0,238 ini lebih besar daripada taraf signifikan $5 \%(0,05)$ sehingga variabel harga $\left(\mathrm{X}_{1}\right)$ berpengaruh tidak signifikan terhadap keputusan pembelian (Y).

2. Variabel rasa $\left(\mathrm{X}_{2}\right)$ mempunyai nilai signifikan 0,783 ini lebih besar daripada taraf signifikan $5 \%(0,05)$ sehingga variabel rasa $\left(X_{1}\right)$ berpengaruh tidak signifikan terhadap keputusan pembelian (Y).

3. Variabel kemasan $\left(\mathrm{X}_{3}\right)$ mempunyai nilai signifikan 0,025 ini lebih kecil daripada taraf signifikan $5 \% \quad(0,05)$ sehingga variabel kemasan $\left(\mathrm{X}_{3}\right)$ berpengaruh signifikan terhadap keputusan pembelian (Y).

\section{Pembahasan}

Pengaruh Secara Bersama - Sama Variabel Bebas (X) Terhadap Variabel Terikat (Y)

Berdasarkan pengujian uji koefisien regresi serempak (Uji F), di ketahui bahwa nilai $F_{\text {hitung }}$ signifikan pada $0.002<$ dari taraf signifikan $5 \%$ (0.05) maka variabel bebas yaitu harga $\left(X_{1}\right)$, rasa $\left(\mathrm{X}_{2}\right)$, kemasan $\left(\mathrm{X}_{3}\right)$, secara bersama - sama berpengaruh terhadap variabel terikat yaitu keputusan pembelian (Y)

\section{Pengaruh Variabel Harga $\left(\mathrm{X}_{1}\right)$ Terhadap Keputusan Pembelian}

Berdasarkan perhitungan uji koefisien regresi secara parsial (Uji t) diperoleh bahwa variabel harga $\left(\mathrm{X}_{1}\right)$ berpengaruh tidak signifikan terhadap keputusan pembelian (Y). Hal ini sesuai dengan harga yang di tetapkan oleh UD Primadona untuk harga satuan proll tape original dengan ukuran besar yaitu sebesar Rp. 25.000. harga tersebut bagi konsumen menengah keatas tidak menjadi masalah, tapi bagi konsumen menengah kebawah harga tersebut terbilang cukup mahal, sehingga konsumen menengah kebawah akan berfikir dua kali untuk membeli proll tape original ukuran besar.

\section{Pengaruh Variabel Rasa $\left(\mathbf{X}_{2}\right)$ Terhadap Keputusan Pembelian}

Berdasarkan perhitungan uji koefisien regresi secara parsial (Uji t) diperoleh bahwa variabel rasa $\left(\mathrm{X}_{2}\right)$ berpengaruh tidak signifikan terhadap keputusan pembelian (Y). Hal ini sesuai dengan keinginan konsumen yang meninginkan variasi rasa atau inofasi rasa pada produk proll tape, dengan adanya inovasi rasa atau variasi rasa konsumen tidak hanya mengkonsumsi proll tape rasa original namun mereka juga bisa mengkonsumsi berbagai rasa yang di sediakan di UD Primadona, sehingga konsumen tidak akan merasa bosan untuk mengkonsumsi produk tersbut.

\section{Pengaruh Variabel Kemasan ( $\left.\mathbf{X}_{3}\right)$ Terhadap Keputusan Pembelian}

Berdasarkan perhitungan uji koefisien regresi secara parsial (Uji t) diperoleh bahwa variabel kemasan $\left(\mathrm{X}_{3}\right)$ berpengaruh signifikan terhadap keputusan pembelian (Y).Hal ini sesuai dengan desain kemasan yang di berikan UD Primadona terhadap produk proll tape yang mana di dalam kemasan tersebut di desain secara rapi dan menarik dan terdapat berbagai informasi mengenai produk proll tape tersebut.

\section{Variabel yang Memiliki Pengaruh Dominan Terhadap Keputusan Pembelian}

Dari analisis data yang dilakukan dapat diketahhui bahwa variabel yang memiliki pengaruh dominan terhadap keputusan pembelian yaitu variabel kemasan $\left(\mathrm{X}_{3}\right)$ hal ini dikarenakan kemasan merupakan salah satu faktor penting yang dibutuhkan konsumen untuk melakukan keputusan pembelian. Selain itu, kemasan juga perlu ditawarkan dengan bentuk dan ciri yang sedemikian menariknya sehingga konsumen bersedia membayar mahal hanya untuk kemasan yang lebih baik.

\section{KESIMPULAN DAN SARAN}

\section{Kesimpulan}

Berdasarkan hasil analisis data maka dapat disimpulkan bahwa : 
1. Variabel harga $\left(X_{1}\right)$, rasa $\left(X_{2}\right)$, kemasan $\left(X_{3}\right)$, secara bersama - sama berpengaruh terhadap variabel terikat yaitu keputusan pembelian (Y)

2. Secara parsial diperoleh kesimpulan bahwa :

a. Variabel Harga $\left(\mathrm{X}_{1}\right)$ berpengaruh tidak signifikan terhadap keputusan pembelian di UD Primadona.

b. Variabel Rasa $\left(\mathrm{X}_{2}\right)$ berpengaruh tidak signifikan terhadap keputusan pembelian di UD Primadona.

c. Variabel Kemasan $\left(\mathrm{X}_{3}\right)$ berpengaruh signifikan terhadap keputusan pembelian di UD Primadona.

3. Variabel yang paling dominan dalam mempengaruhi keputusan pembelian di UD Primadona J1. Trunojoyo No. 137 Jember adalah varibel kemasan.

\section{Saran}

1. Berdasarkan hasil penelitian maka peneliti menyarankan untuk penelitian yang akan datang sebaiknya meneliti variabel lain yang tidak dimasukan dalam penelitian ini, seperti variabel tekstur, dan variabel warna dari proll tape yang ada di UD. Primadona, karena munculnya sebuah perilaku pembelian konsumen merupakan akibat dari banyak faktor lain.

2. Bagi UD Primadona perlu juga memperhatiakan kualitas dari produk proll tape dengan cara meningkatkan produk proll tape itu dari segi rasa agar konsumen tidak beralih keproduk yang lain.

\section{DAFTAR PUSTAKA}

Arikunto, S. 2013. Prosedur Penelitian Suatu Pendekatan Praktik. Jakarta:RinekaCipta.

Armstrong, G. Kotler, P. 2008.Prinsip-prinsip Pemasaran. Jakarta: Erlanga.

Boyd, H.W., O.C. Walker, J.C. Larreche. 2000. Manajemen Pemasaran. Jakarta: Erlangga.
Dewi, Ade Kurnia. 2012. "Pengaruh Atribut Produk Terhadap Keputusan Pembelian "Pia Glenmore" Banyuwangi." Tugas Akhir. Progam Studi Manajemen Agroindustri. Jurusan Manajemen Agribisnis Politeknik negeri Jember.

Frestiyanto, I. 2010. Analisis Faktor-Faktor Yang Mempengaruhi Keputusan Pembelian Produk Rokok Nojorono. Semarang. UniversitasDiponegoro.

Guiltinan, J.P., dan G.W. Paul. 1990. Strategi dan Progam Manajemen Pemasaran. Jakarta: Erlangga.

Kotler, P dan Keller, K. 2008.Manajemen Pemasaran. Jakarta: Erlanga.

Kotler, Philip dan Keller, Kevin Lane. 2009."Manajemen Pemasaran”. Edisi 12. Jilid 1. Jakarta : Erlangga.

Puspita, B. 2007.Analisis Pengaruh Atribut Produk Terhadap Keputusan Pembelian Kebab Turky Baba Rafi Di Yogyakarta.Yogyakarta.Universitas Islam Indonesia.

Sugiyono.2011. Statistika Untuk Penelitian. Alfabeta.Bandung.

Sugiyono, 2009.Metode Penelitian Kuantitatif Kualitatif Dan R\&D. Bandung: Alfabeta.

Sutojo, S. 1988. Kerangka Dasar Manajemen Pemasarran: Dharma AksaraPerkasa.

Winarno, 2002.Flavor Bagi IndustriPangan. Bogor : M-Brio Press.

Winardi. 1991. Marketing dan Prilaku Konsumen. Bandung: Mandar Maju.

Wiguna, SP (2007), "Pengaruh Kemasan Produk Terhadap Keputusan Konsumen Dalam Membeli Produk Jajanan Khas kota Gresik" Skripsi. Fakultas Ekonomi. Jurusan Manajemen 